\title{
Penentuan Tenaga Kerja Optimal pada Packaging Kopi dengan Menggunakan Analisis Beban Kerja Metode Work Sampling
}

\section{Determination of the Optimal Workforce on Coffee Packaging Using Workload Analysis with the Work Sampling Method}

\author{
Deltaningtyas Tri Cahyaningrum ${ }^{\# 1}$, Nurhadi Siswanto ${ }^{* 2}$, Hendy Firmanto*3 \\ ${ }^{\#}$ Manajemen Agribisnis, Politeknik Negeri Jember \\ 1e-mail: deltaningtyasepolije.ac.id
}

\begin{abstract}
The effectiveness, efficiency, and productivity of the company are very much determined by the workload. By knowing the workload, a company can find out the optimum number of workers needed to meet the target. This is also important for the Indonesian Coffee and Cocoa Research Center, especially in the processing of coffee in the packaging section. Therefore a workload analysis will be carried out using the Work Sampling Method. From the results of the work sampling method, it can be seen that worker productivity is 0.90697 , as well as a rating factor of 0.09 and an allowance of 22 . With these results it can be calculated that the standard time needed by workers in coffee packaging is $\mathbf{1 0 . 9 8}$ minutes and the optimum number of workers required 2.06 people.
\end{abstract}

Keywords: workload, work sampling method, productivity, rating factor, standard time.

\section{Pendahuluan}

Efektivitas, efisiensi dan produktivitas penting dalam sebuah organisasi. Ketiga hal tersebut sangat erat kaitannya dengan beban kerja yang dilakukan oleh pekerja. Untuk mengefisiensikan beban kerja dilakukan analisis beban kerja pada pekerja. Dengan mengetahui beban kerja, suatu organisasi dapat menentukan jumlah sumber daya manusia optimal yang digunakan untuk mencapai target.

Sumber daya manusia merupakan faktor yang mempengaruhi proses produksi. Ketersediaan sumber daya manusia dengan tingkat keterampilan yang memadai serta dengan jumlah yang tepat menjadi hal penting dalam memproduksi produk[1]. Khususnya pada bagian packaging produk yang nantinya harus sesuai dengan keinginan pelanggan. Oleh karena itu dilakukan pegukuran kerja dengan metode work sampling. Metode ini bertujuan untuk mengetahui waktu kerja yang dibutuhkan oleh pekerja dengan mempertimbangkan faktor-faktor yang mempengaruhi aktivitas pekerja.
Pusat Penelitian Kopi dan Kakao Indonesia, khususnya pada Laboratorium Pengolahan Kopi bagian packaging akan dilakukan pengukuran kerja untuk menentukan waktu standar dengan metode work samplingsehingga akan diketahui jumlah pekerja optimum pada bagian tersebut.Kondisi pekerja di Laboratorium Pengolahan Kopi tidak memiliki deskripsi kerja yang jelas sehingga ketika kekurangan pekerja maka pekerja di laboratorium pengolahan lain dapat dipindahkan.

Berdasarkan permasalahan pemindahan pekerja akan dilakukan penelitian dengan menghitung beban kerja serta waktu standar untuk packaging kopi khususnya ketika memasukkan kopi. Penelitian ini nantinya dapat menjadi acuan untuk menentukan jumlah pekerja optimum yang dibutuhkan.

\section{Metode}

Langkah pertama penelitian yang dilakukan adalah studi literatur dengan menggunakan metode work sampling. Langkah-langkah yang dilakukan ditunjukkan pada Gambar 1. 


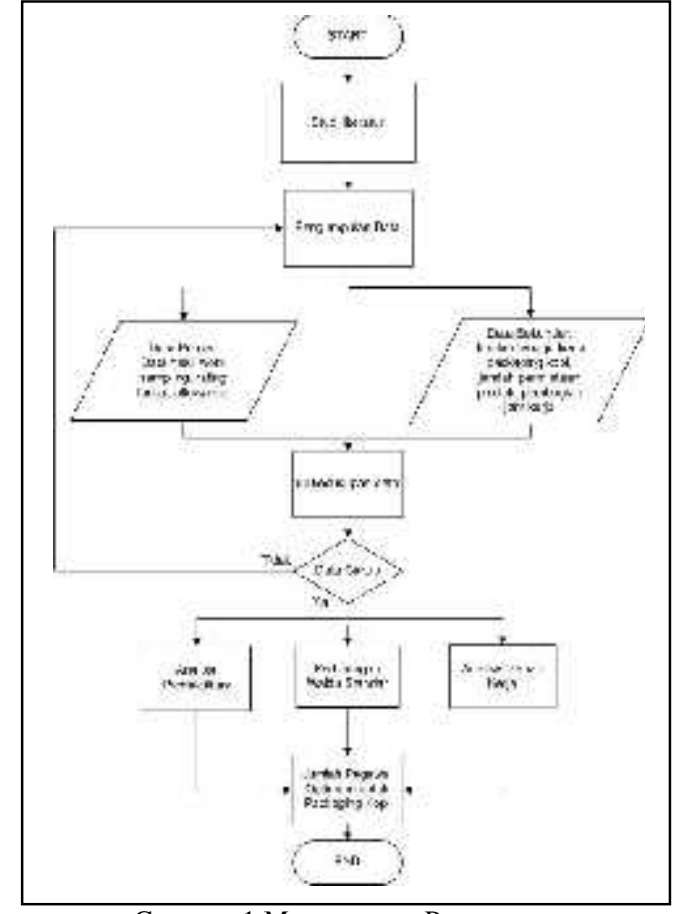

GAMBAR 1:METODOLOGI PENELITIAN

\section{A. Metode Work Sampling}

Metode Work Sampling merupakan suatu teknik untuk mengadakan sejumlah pengamatan terhadap aktifitas kerja dari mesin, proses atau operator [2]. Pengambilan data dengan menggunakan metode ini harus dilakukan secara langsung di tempat kerja yang diteliti. Metode Work Sampling ini dikembangkan berdasarkan hukum probabilitas atau sampling. Oleh karena itu pengamatan terhadap suatu obyek yang ingin diteliti tidak perlu dilaksanakan secara menyeluruh (populasi) melainkan cukup dilakasanakan dengan mengambil sampel pengamatan yang diambil acak.

Manfaat dari work sampling yaitu mengukur rasio delay-activity, mengukur allowance time, menetapkan performance rating, menetapkan proporsi dari kegiatan serta waktu baku bagi operator. Namun, dibutuhkan elemen kerja working dan not working dalam pengambilan data.

Elemen kerja working adalah elemen kerja yang dilakukan oleh karyawan. Sedangkan elemen kerja not working merupakan elemen kerja yang dilakukan karyawan di luar prosedur yang ada. Untuk pengambilan data dilakukan pada tahapan pre work sampling sampai work sampling hari ke - 3 untuk mendapatkan data yang cukup.

Pengujian kecukupan data pada pengamatan pre work sampling dan work sampling dengan rumus sebagai berikut:

$$
N^{\prime}=\frac{z^{2} p-q}{S^{2}}
$$

Dengan:

$\mathrm{p}$ adalah proporsi working dibanding dengan total

q adalah 1-p

$\mathrm{S}$ adalah nilai tingkat kepercayaan

$\mathrm{z}$ adalah nilai statistik dari tingkat kepercayaan.

\section{B. Rating Factor dan Allowance}

Dalam menentukan rating factor pada pekerja, digunakan metode westinghouse dengan menilai empat faktor dalam bekerja, yaitu skill, effort, condition, consistency. Tabel westinghouse ditunjukkan pada Tabel 1.

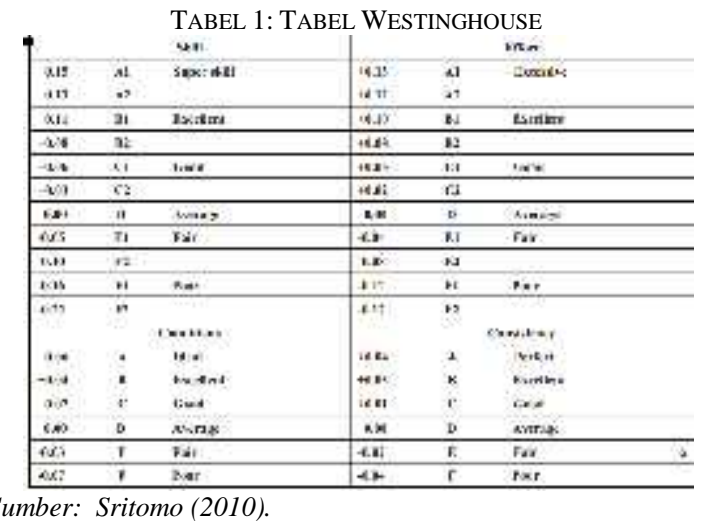

Setelah diketahui rating factor dari pekerja, maka selanjutnya dilakukan perhitungan allowance. Allowance merupakan waktu yang dibutuhkan karyawan dalam melakukan kebutuhan probadi, menghilangkan rasa fatique serta kegiatan yang tidak dapat dihindarkan. Beberapa kelonggaran ditunjukkan pada Gambar 2.

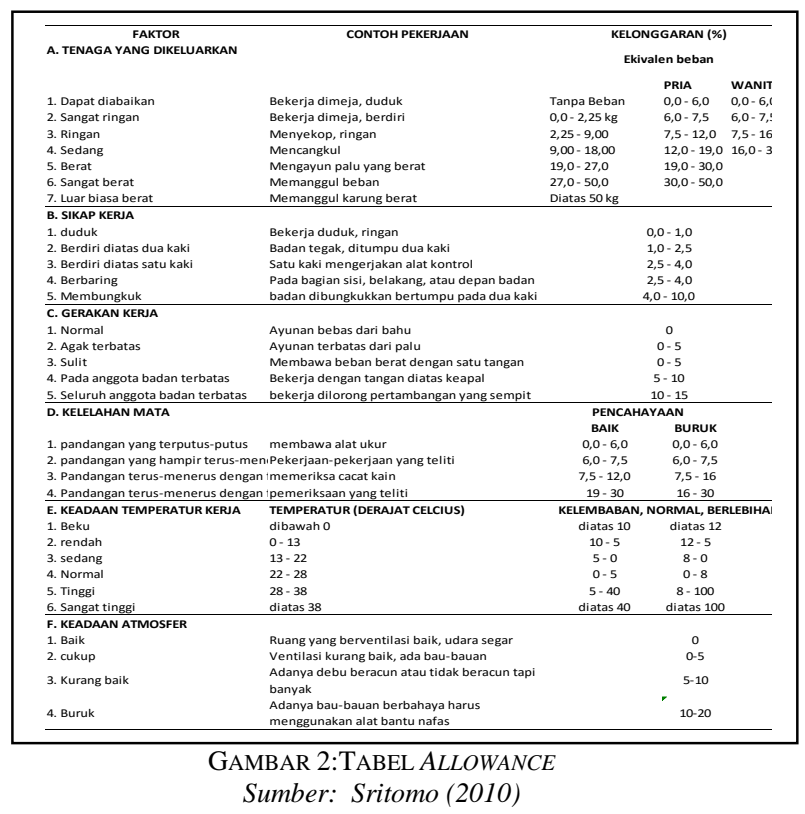

Setelah melakukan pengamatan terhadap rating factor serta allowance pekerja, selanjutnya dilakukan 
Deltaningtyas Tri Cahyaningrum. Penentuan Tenaga Kerja Optimal pada Packaging Kopi dengan Menggunakan Analisis Beban Kerja Metode Work Sampling

perhitungan waktu standar. Waktu standar dilakukan untuk mengetahui waktu yang dibutuhkan dalam melakukan kegiatan. Rumus waktu standar adalah sebagai berikut:

$$
\text { Ws }=\frac{T \mathrm{TT} \times W \mathrm{~T} \times \mathrm{RF}}{\sum \mathrm{Yi}} \times \frac{100}{100-\text { Allowance }}
$$

Dengan:

TT adalah Total Time

WT adalah Working Time

RF merupakan Rating Factor

$\Sigma Y$ i adalah Jumlah produk yang dihasilkan

Tahap selanjutnya dengan menghitung tenaga kerja optimum yang dibutuhkan. Perhitungan tenaga kerja optimum membutuhkan waktu total serta jumlah permintaan produk. Setelah didapatkan data tersebut dilakukan perhitungan sebagai berikut:

$$
\mathrm{Wt}=\mathrm{Ws} \times \mathrm{Yi}
$$

Dengan:

Ws adalah waktu standar

Yi adalah jumlah permintaan produk

$\mathrm{JKP}=$ Total waktu kerjá periode $\times 60$ menit

$$
\mathrm{JTK}=\frac{\mathrm{Wt}}{\mathrm{IKP}}
$$

Dengan:

Wt adalah waktu total

JKP adalah Jumlah waktu periode

\section{III.HASIL DAN DISKUSI}

Dilakukan pencarian elemen kerja working pada packaging kopi, khususnya pada tahap memasukkan kopi. Sehingga elemen kerja working adalah

1. Mengambil kemasan

2. Menjawab atau melakukan panggilan telepon kantor

3. Memasukkan kopi dalam kemasan

4. Mengangkat bak berisi kopi

5. Merapikan ruangan

6. Melakukan pelayanan kepada rekan kerja

Sedangkan elemen kerja not working pada packaging kopi dengan tahapan yang sama adalah:

1. Fatique (contoh: pelemasan, menguap)

2. Not available (contoh: sms/telepon dengan ponsel pribadi)

3. Personal time (contoh: kamar mandi, makan minum, sholat, istirahat)

Dengan dilakukan pengambilan data, dihasilkan total data yang dibutuhkan 160. Dari data tersebut dilakukan uji kecukupan data dengan perhitungan working not working [3]. Rekap data ditunjukkan

\begin{tabular}{|c|c|c|c|}
\hline Pengamatan & Working & Not Working & Total \\
\hline Pre Work Sampling & 82 & 18 & 100 \\
\hline $\begin{array}{c}\text { Work Sampling Hari } \\
1\end{array}$ & 29 & 3 & 32 \\
\hline Work Sampling Hari & 22 & 3 & 25 \\
\hline $\begin{array}{c}\text { Work Sampling Hari } \\
3\end{array}$ & 3 & 0 & 3 \\
\hline Total & 136 & 24 & 160 \\
\hline
\end{tabular}
pada Tabel 2.
TABEL 2: REKAP DATA WORKING-NOT WORKING

Sumber: Hasil Perhitungan.

Setelah mendapatkan data yang dimiliki, dilakukan pengujian kecukupan data menggunakan rumus (1). Hasil dari pengujian ditunjukkan pada

\begin{tabular}{|c|c|c|c|c|}
\hline Pengamatan & $\mathbf{N}$ & $\mathbf{N}^{\prime}$ & Keterangan & \\
\hline Pre Work Sampling & 100 & 227 & $\begin{array}{l}\mathrm{N}<N^{\prime} \text { Sehingga Data } \\
\text { Tidak Cukup }\end{array}$ & \\
\hline $\begin{array}{l}\text { Work Sampling } \\
\text { Hari } 1\end{array}$ & 132 & 206 & $\begin{array}{l}\mathrm{N}<\mathrm{N}^{\prime} \text { Sehingga Data } \\
\text { Tidak Cukup }\end{array}$ & \\
\hline $\begin{array}{l}\text { Work Sampling } \\
\text { Hari } 2\end{array}$ & 157 & 162 & $\begin{array}{l}\mathrm{N}<\mathrm{N}^{\prime} \quad \text { Sehingga } \\
\text { Tidak Cukup }\end{array}$ & Data \\
\hline $\begin{array}{c}\text { Work Sampling } \\
\text { Hari } 3\end{array}$ & 160 & 0 & $\begin{array}{l}N>N^{\prime} \quad \text { Sehingga } \\
\text { Cukup }\end{array}$ & Data \\
\hline
\end{tabular}
Tabel 3.

TABEL 3: REKAP HASIL UJI KECUKUPAN DATA

Sumber: Hasil Perhitungan.

Berdasarkan Tabel 3, data yang diambil dapat diproses ke tahap selanjutnya. Dari data tersebut dilakukan perhitungan produktivitas sehingga produktivitas yang dihasilkan oleh pekerja packaging kopi adalah 0,90697 dengan jumlah produk 45 . Rekapitulasi produktivitas pekerja ditunjukkan pada Tabel 4.

\begin{tabular}{lcccc}
\multicolumn{3}{c}{ TABEL 4: REKAPITULASI PRODUKTIVITAS PEKERJA } \\
\hline Pengamatan Working & $\begin{array}{c}\text { Not } \\
\text { Working }\end{array}$ & Total & $\begin{array}{c}\% \\
\text { Produktivitas }\end{array}$ \\
\hline $\begin{array}{c}\text { Work } \\
\text { Sampling } \\
\text { Hari 1 }\end{array}$ & 111 & 21 & 132 & 0,840909 \\
$\quad \begin{array}{l}\text { Work } \\
\text { Sampling } \\
\text { Hari 2 }\end{array}$ & 22 & 3 & 25 & 0,88 \\
$\quad \begin{array}{l}\text { Work } \\
\text { Sampling } \\
\text { Hari 3 }\end{array}$ & 3 & 0 & 3 & \\
Rata - rata & & & \\
\hline
\end{tabular}

Sumber: Hasil Perhitungan

Dengan menggunakan Tabel westinghouse yaitu Tabel 1, dapat diketahui rating factor pada pekerja packaging kopi adalah 0,09. Ditunjukkan pada Tabel 5. 
Jurnal Ilmiah INOVASI, Vol. 21 No. 1 Januari-April 2021, ISSN 1411-5549

TABel 5: Rating Factor PeKerJa PACKAGING KoPI

\begin{tabular}{cll}
\hline No & \multicolumn{1}{c}{ Rating Factor } & Nilai \\
\hline 1 & Skill : Good $(\mathrm{C} 1)$ & 0,06 \\
2 & Effort : Good $(\mathrm{C} 1)$ & 0,05 \\
3 & Condition : Fair $(\mathrm{E})$ & $-0,03$ \\
4 & Consistency : Good $(\mathrm{C})$ & 0,01 \\
& Total & 0,09 \\
\hline & Sumber: & Pengamatan Langsung.
\end{tabular}

Setelah mendapatkan nilai rating factor, dilakukan pencarian allowance berdasarkan Gambar 2. Allowance yang dihasilkan oleh pekerja packaging kopi adalah

1. Tenaga kerja yang dikeluarkan sesuai hasil pengamatan: bekerja duduk, mengeluarkan tenaga untuk menyekop kopi ke plastik

2. Sikap kerja sesuai hasil pengamatan: bekerja duduk

3. Gerakan kerja sesuai hasil pengamatan: gerakan kerja agak terbatas

4. Kelelahan mata pada pegawai sesuai hasil pengamatan: pandangan yang terputus-putus

5. Keadaan temperatur kerja adalah temperatur kerja dalam keadaan sedang

6. Keadaan atmosfer cukup, karena ventilasi kurang serta ada bau-bauan

Dari penjelasan tersebut, rating factor yang didapat ditunjukkan pada Tabel 6 .

TABel 6: RATING FACTOR PEKERJA PACKAGING KOPI

\begin{tabular}{clc}
\hline No & \multicolumn{1}{c}{ Rating Factor } & Nilai \\
\hline 1 & Tenaga yang dikeluarkan & 8 \\
2 & Sikap Kerja & 1 \\
3 & Gerakan Kerja & 3 \\
4 & Kelelahan Mata & 4 \\
5 & Keadaan Temperatur Kerja & 4 \\
6 & Keadaan Atmosfer & 3
\end{tabular}

Total

Sumber: Pengamatan Langsung.

Setelah mendapatkan seluruh nilai, maka dilakukan perhitungan waktu standar packaging kopi dengan rumus (2). Sehingga nilai waktu standar dari pekerja adalah 10,9844144.

Dengan didapatnya waktu standar, selanjutnya dilakukan perhitungan pada rumus (3) dan (4) untuk mendapatkan jumlah tenaga kerja optimum. Diberikan data permintaan produk kopi 250 gram setahun, sehingga dapat dihitung waktu totalnya hingga jumlah tenaga kerja.

$$
\begin{aligned}
\mathrm{Wt} & =\mathrm{Ws} \times \mathrm{Yi} \\
& =10,9844144 \text { menit } \times 1859 \\
& =20420,0263696 \text { menit }
\end{aligned}
$$

$\mathrm{JKP}=$ Total waktu kerja periode $\mathrm{x} 60$ menit

$$
\begin{aligned}
& =25,42 \text { hari } \times 6,5 \text { jam } \times 60 \text { mennit } \\
& =9912,5 \text { menit }
\end{aligned}
$$

JTK $=\frac{20420,0263696}{9912,5}=2,06 \approx 3$ orang

Sehingga, dari perhitungan tersebut didapatkan jumlah tenaga kerja optimum 3 orang.

\section{IV.KESIMPULAN}

Kesimpulan yang dapat diambil dari penelitian pengukuran kerja pada pekerja packaging kopi adalah:

Waktu standar yang dibutuhkan oleh pekerja dalam packaging kopi, khususnya memasukkan kopi adalah 10,9844144 menit. Tenaga kerja optimum yang dibutuhkan adalah 3 orang.

\section{DafTAR PUSTaKa}

[1]. Nanda Wibawa, R. P., S. \& Efranto, R. Y., 2014. Analisis Beban Kerja Dengan Metode Workload Analysis Sebagai Pertimbangan Pemberian Insentif Pekerja. Studi Kasus di Bidang PPIP PT Barata Indonesia (Persero) Gresik, pp. 672-683.

[2]. Nurjanah, Piqih. 2009. Penentuan Jumlah Tenaga Kerja Berdasarkan Waktu Standar dengan Metode Work Sampling di Bagian Packing pada PT. Sinar Oleochemical International. Universitas Sumatera Utara. Medan.

[3]. Wignjosoebroto, Sritomo. 2010.Studi Gerak dan Waktu Edisi Pertama. Institut Teknologi Sepuluh Nopember. Surabaya. 